\title{
EFFECT OF TEMPERATURE ON THE FATIGUE LIFE OF NATURAL RUBBER
}

\author{
Can Zhang, Aleksander Czekanski \\ Department of Mechanical Engineering, York University, Toronto, Canada \\ alex.czekanski@lassonde.yorku.ca
}

\begin{abstract}
Natural rubber is widely used in industrial applications owning to its good elasticity and ductility. Studying the fatigue performance of rubber is important, as it affects the service life of rubber products. This paper focuses on how temperature affects the fatigue lifetime of natural rubber during tensile testing. The fundings of tensile testing show that below $50{ }^{\circ} \mathrm{C}$, proper heating can increase the lifetime of natural rubber. However, when the temperature exceeds $50{ }^{\circ} \mathrm{C}$ and continues to increase, the fatigue life of rubber decreases. Different crack propagation modes dominate at different temperatures, resulting in different fracture surfaces.
\end{abstract}

Keywords-component; natural rubber; fatigue lifetime; temperature

\section{INTRODUCTION}

Owing to superior elasticity and large deformation capacity, rubber is ideal for use in a wide array of components such as vibration isolators, belts, seals, and medical devices in the machinery, automotive, and biomedical industries, among many others [1]. Rubber components are subjected to performance tests to ensure their durability - including evaluation of heat resistance, fatigue resistance, and aging resistance under the large variety of environmental conditions to which the components will be exposed. The complex working environment sets stringent requirements for the comprehensive performance of rubber. This includes the working environment for a mechanical structure with rubber dampers, which will be subjected to various forms of loading during its normal service life, and therefore will need to run reliably for a considerable length of time. Fatigue behavior is one important characteristic that affects the life of rubber products. Therefore, it is necessary to evaluate the fatigue life of rubber dampers under different conditions to better understand how to measurably improve their longevity.

Many environmental factors affect the fatigue life of rubber products, temperature, humidity, frequency, and loading chief among them. Since temperature greatly influences the fatigue life of rubber, this work demonstrates how to establish a protocol, using the Intron Dynamic Test Instrument, to test a natural rubber sample at different temperatures under $50 \%$ strain control. The result of this study will improve our understanding of the relationship between temperature and the number of fatigue life cycles of a natural rubber specimen and the nature of the specimen's fracture surface.

The fatigue failure of rubber refers to the phenomenon that the physical properties of the material are reduced under the effect of periodic deformation or applied force. Crack nucleation and crack growth are two common approaches used in current studies of rubber fatigue [2]. At the micro level, these approaches focus on predicting where a crack first appears in a rubber sample as well as the growth of existing cracks or flaws [3]. The two main parameters in the crack nucleation approach are the maximum principal strain and strain energy density [4]. It is easy to obtain the maximum principal strain of rubber by calculating displacement. The maximum principal strain is usually used to characterize the crack nucleation life of rubber; this crack is usually generated in a plane perpendicular to the direction of the maximum principal strain [5].

Strain-induced crystallization (SIC) plays a role of paramount importance in natural rubber fatigue resistance, as it prevents crack initiation and prolongs the life of natural rubber. Ruellan et al. (2018) investigated the effect of temperature on rubber fatigue [2]. Although temperature does not affect crack initiation, it influences the SIC related to crack growth. With an increase in the temperature, a lower lifetime reinforcement without any marks of SIC was observed at the fracture surfaces; this means that the cracks will grow. Le Cam et al. (2017) found that under different uniaxial loading conditions, a crack can initiate in different areas but will not appear in the middle of a diabolo natural rubber specimen [6]. Different types of cyclic loading conditions lead to different types of fatigue damage in crystallizable rubbers, indicating that the influence of loading conditions on fatigue life should be discussed when considering SIC. 
We therefore focused on the macroscopic scale for fatigue testing at $50 \%$ strain loadings under different temperatures.

\section{EXPERIMENTAL SETUP}

\section{A. Geometry of specimen}

Since buckling does not occur under compression, and fatigue damage usually occurs only on the surface of samples, volumetric samples are more representative of rubber parts than plane samples in adapting to fatigue [2]. The material used in this study was natural rubber with shore A hardness of 55. Figure 1 shows the geometry of the specimen, which was purchased from Elesa Corporation. This specimen contains zinc-plated steel plates and threaded studs that can be easily fixed.

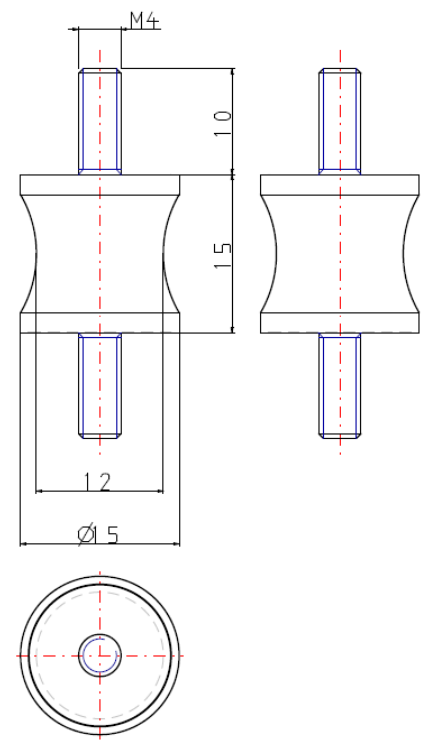

Fig. 1. Configurations of the specimen

\section{B. Loading conditions}

In the uniaxial tension test, the loading condition $R=\frac{\varepsilon_{\min }}{\varepsilon_{\max }}$ can be divided into three part. When $\mathrm{R}>0$, the resulting condition is tension-tension, which means the maximum strain and minimum strain are $>0$. When $\mathrm{R}<0$, the resulting condition is tension-compression, which means the mean strain and maximum strain are $>0$ and the minimum strain is $<0$. When $\mathrm{R}=0$, the resulting condition is fully relaxing tension, which means that the minimum strain $=0$. This study focuses on the fully relaxing tension condition when $\mathrm{R}=0$, where mean strain is $25 \%$ and maximum strain is $50 \%$.

\section{Temperature condition}

A polymer substance has three states: glass state, rubberelastic state and viscosity flow state. In the glass state, the molecular chain of the polymer barely moves; it becomes very brittle, like glass, and loses its elasticity. When the temperature rises above the glass transition temperature $\left(T_{\mathrm{g}}\right)$, a polymer exhibits the rubber-elastic state. In this state, a polymer shows very good elasticity and motion of the molecular chain segment is intensified, but there is no slip between molecular chains. After a force is applied, resulting in a large deformation, the polymer can still return to its initial position. When the temperature is greater than viscosity flow temperature ( $T_{\mathrm{f}}$ ), owing to the overall movement of the molecular chain, the polymer begins to enter the viscosity flow state. In this state, the polymer melt can cause macroscopic flow under the action of a small external force.

For natural rubber, $T_{\mathrm{g}} \approx-70^{\circ} \mathrm{C}$ and $T_{\mathrm{f}} \approx 130^{\circ} \mathrm{C}$. Thus, natural rubber products usually work best in this temperature range. In this study, the experiment exposes specimens temperatures of $23{ }^{\circ} \mathrm{C}, 50^{\circ} \mathrm{C}$ and $80{ }^{\circ} \mathrm{C}$.

Therefore, the specimen was tested under uniaxial $50 \%$ strain fully relaxing tension at $23^{\circ} \mathrm{C}, 50{ }^{\circ} \mathrm{C}$ and $80^{\circ} \mathrm{C}$ by using a $10 \mathrm{~Hz}$ sine waveform. The criterion of failure in this fatigue test is that the specimen fractures completely.

\section{RESULTS AND DISCUSSION}

\section{A. Effect of temperature on fatigue life}

Figure 2 shows the relationship between fatigue life and temperatures. At $23{ }^{\circ} \mathrm{C}$, the fatigue life of specimen is $\sim 52,000$ cycles. When the temperature increases to $50{ }^{\circ} \mathrm{C}$, fatigue life increases to $\sim 62,000$ cycles; however it decreases to 46,000 cycles if the temperature rises to $80{ }^{\circ} \mathrm{C}$.

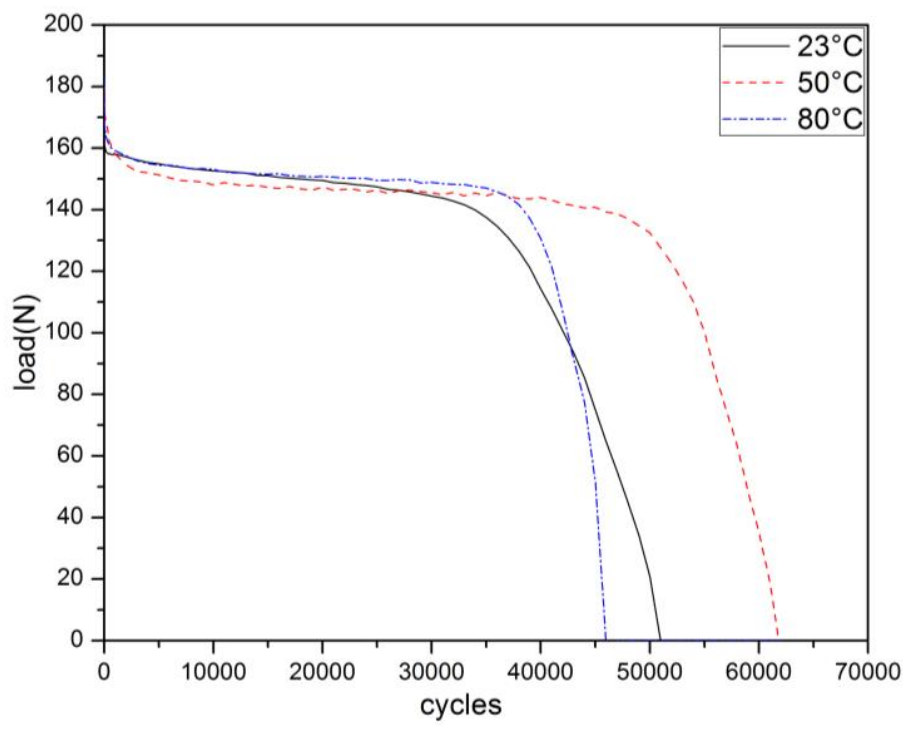

Fig. 2. Fatigue life cycles and loading at different temperatures

When the temperature reaches $\sim 50{ }^{\circ} \mathrm{C}$, heat increases molecular mobility, allowing the stress relaxation rate increase. This leads to a decrease in stress concentration. The lower stress concentration reduces the chance of molecular chains 
breaking, making it harder to fatigue the natural rubber specimen.

However, as the temperature rises to $\sim 80{ }^{\circ} \mathrm{C}$, poor thermal conductivity makes it difficult for the rubber specimen to dissipate fatigue heat. The higher the temperature rises, the more likely it is that the heat will cause thermomechanical damage, and more likely that increased thermal oxidation will accelerate fatigue.

Proper heating can extend the fatigue life of rubber, but the heat generated by too high a temperature will accelerate the breakage of the molecular chains, which will accelerate fatigue.

\section{B. Fracture surface at a macroscopic scale}

The initial crack always appears on or near the surface of the coupon. The reason why is that during the uniaxial tension test, the total length of the coupon becomes longer and the cross-sectional area becomes smaller. The largest deformation of the specimen occurs on the outer surface, which causes the most violent molecular chain movement. Therefore, it is easy for stress concentrate in this region. The direction of crack growth is usually perpendicular to the load. Figure 3 shows the crack's initial appearance in the middle of the specimen and the direction of its propagation.

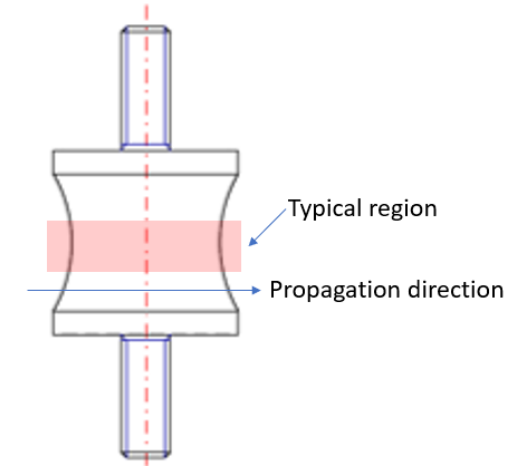

Fig. 3. Crack initiation and direction of propagation

The fracture surface, from left to right (propagation direction), can be divided into three zones: crack initiation, crack growth and final ligament. The initiation zone is always located close to the surface of the sample. There are some tiny wrenchings in this zone. The crack growth zone relates to crack propagation through the bulk of the specimen. It is covered by many wrenchings and looks very rough. The final ligament zone is smooth, and with breakage of the entire area occurring at the same time. Figure 4 shows the fracture area surface obtained from experiments performed at $50{ }^{\circ} \mathrm{C}$. The specimen tested at $23{ }^{\circ} \mathrm{C}$ has similar crack initiation and propagation characteristics.

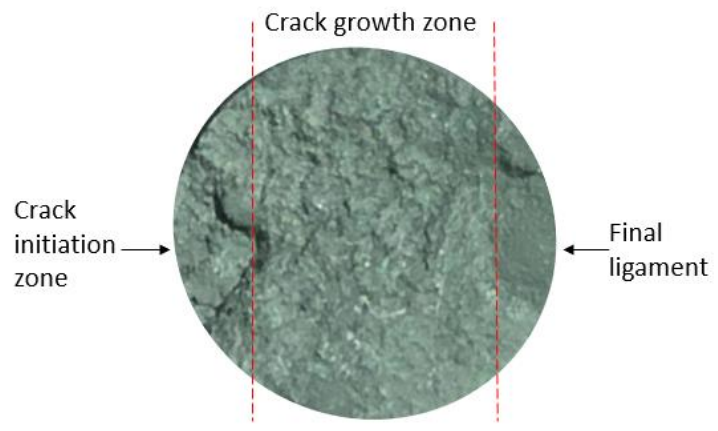

Fig. 4. Schematic view of the fracture surface at $50^{\circ} \mathrm{C}$

However, the fracture area surface at $80{ }^{\circ} \mathrm{C}$ (Fig.5) has different appearance. From left to right, the fracture surface has two distinct areas. From the top view, a river-like line appears in the crack propagation zone. From the front view, the fracture area is not flat but has obvious bumps, and the crack propagation direction is slightly obliquely upward. Compared with the fracture area at $23{ }^{\circ} \mathrm{C}$, this surface does not have a final ligament zone. The crack coalesces at the end of the fatigue life.

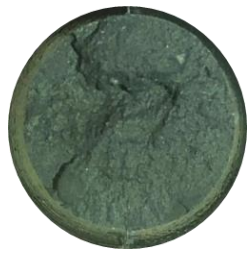

(a) Top view

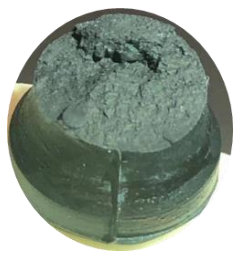

(b) Front view
Fig. 5. Schematic view of the fracture surface at $80^{\circ} \mathrm{C}$

\section{CONCLUSION}

Temperature will affect the fatigue lifetime of natural rubber. At less than $50{ }^{\circ} \mathrm{C}$, proper heating can increase the lifetime of natural rubber. But when the temperature exceeds $50{ }^{\circ} \mathrm{C}$, the fatigue life of rubber decreases with increasing temperature. Different crack propagation modes at different temperatures result in fracture surfaces that are different. Fracture surface depends on temperature.

\section{REFERENCES}

[1] Wu, J., Chen, L., Li, H., Su, B., and Wang, Y. (2018). Effect of Temperature on Tensile Fatigue Life of Natural Rubber, IOP Conf. Ser.: Mater. Sci. Eng. 389012024

[2] Cruanes, C., Lacroix, F., Berton, G., Meo, S., and Ranganathan, N. (2015). Study of the Fatigue Behavior of a Synthetic Rubber Undergoing Cumulative Damage Tests, International Journal of Fatigue, 91 (2016), 322-327. doi: https://doi.org/10.1016/j.ijfatigue.2015.11.026. I. S. Jacobs and C. P. Bean, "Fine particles, thin films and exchange anisotropy," in Magnetism, vol. III, G. T. Rado and H. Suhl, Eds. New York: Academic, 1963, pp. 271-350.

[3] Ruellan, B., Le Cam, J.-B., Jeanneau, I., Canevet, F., Mortier, F., and Robin, E. (2018). Fatigue of natural rubber under different temperatures, International Journal of Fatigue (2018), doi: https://doi.org/10.1016/j.ijfatigue.2018.10.009.R. Nicole, "Title of paper with only first word capitalized," J. Name Stand. Abbrev., in press.

[4] Moon, S., Cho, I., Woo, C., and Kim, W. (2011). Study on Determination of Durability Analysis Process and Fatigue Damage Parameter for Rubber Component, Journal of Mechanical Science and 
Technology, $25 \quad$ (5) (2011), 1159-1165. doi: https://doi.org/10.1007/s12206-011-0221-6.

[5] Mars, W., Fatemi, A. (2002). A Literature Survey on Fatigue Analysis Approaches for Rubber, International Journey of Fatigue, 24 (2002), 94996
[6] Ruellan B. et al. (2020). A Post Mortem Analysis of the Strain-Induced Crystallization Effects on Fatigue of Elastomers. In: Silberstein M., Amirkhizi A., Shuman X., Beese A., Berke R., Pataky G. (eds) Challenges in Mechanics of Time Dependent Materials, Fracture, Fatigue, Failure and Damage Evolution, Volume 2. Conference Proceedings of the Society for Experimental Mechanics Series. Springer, Cham 